\title{
Cervical carcinogenesis: The role of co-factors and generation of reactive oxygen species
}

\author{
Anna Giuliano, PhD.(1)
}

\section{Giuliano A. \\ Cervical carcinogenesis:The role of co-factors and generation of reactive oxygen species. Salud Publica Mex 2003;45 suppl 3:S354-S360. This paper is available too at: http://www.insp.mx/salud/index.html}

\begin{abstract}
A bstract
Several HPV co-factors have been proposed, some more or less consistently associated with cervical dysplasia and cancer risk. More research, using prospective cohort designs, is needed to further describe where in carcinogenesis these factors are working and to assess the biological mechanism of these factors. In addition, further research is needed to define the role of various hormonal contraceptive formulations in promoting cervical carcinogenesis. W hile many interesting scientific questions remain to be answered, results from the numerous epidemiological studies conducted to date indicate that cervical dysplasia and cancer may be reduced if the oxidant antioxidant ratio is shifted to more of and antioxidant profile. In addition to cervical cancer screening, a reduction in cervical cancer incidence may be accomplished by reducing to bacco use, increasing nutritional status, and utilizing barrier contraception to prevent infection with other sexually acquired infections. This paper is available too at: http:// www.insp.mx/salud/index.html
\end{abstract}

Key words: cervical cancer; co-factors; antioxidant; nutrition; prevention

\section{Giuliano A. \\ Carcinogénesis cervical: co-factores \\ y antioxidantes.}

Salud Publica Mex 2003;45 supl 2:S354-S360.

Este artículo también está disponible en:

http://www.insp.mx/salud/index.html

\section{Resumen}

Diversos co-factores de riesgo han sido asociados consistentemente con displasia cervical y cáncer invasor. Es necesario un mayor número de investigaciones que utilicen diseños de cohorte prospectivos para describir el proceso de carcino génesis y el mecanismo biológico de cada uno de estos factores. Adicionalmente, futuras investigaciones serán necesarias para definir el papel de los anticonceptivos hormonales en la promoción de la carcinogénesis cervical. Mientras que muchas preguntas científicas interesantes permanecen sin ser respondidas, resultados de numerosos estudios epidemiológicos que se desarrollan actualmente, indican que la displasia cervical y cáncer podrán ser reducidos si la tasa de oxidantes-antioxidantes es cambiada a más de un perfil antioxidante.A demás de la detección oportuna de cáncer cervical, puede lo grarse una reducción de la incidencia de esta enfermedad disminuyendo el consumo de tabaco, incrementando el estatus nutricional, y utilizando métodos contraceptivos de barrera para prevenir otras infecciones de transmisión sexual. Este artículo también está disponible en: http://www.insp.mx/salud/index.html

Palabras clave: cáncer cervical; co-factores de riesgo; antioxidantes; nutrición; prevención

(1) Associate Professor of Public Health, Co-Director, Cancer Prevention and Control Program, Arizona Cancer Center, University of Arizona, Tucson, AZ, USA.

Received on: September 17, 2002 • Accepted on: February 17, 2003 
nternationally, invasive cervical cancer accounts for $9.8 \%$ of all cancers. ${ }^{1,2}$ In 1996 , approximately 525000 new cases of cervical cancer were diagnosed. It is the second most common cancer among women living in less developed countries. In the United States, approximately 12900 new cases of invasive cervical cancer were diagnosed, and 4400 women died of this cancer in $2001 .{ }^{3}$ Nationally, morbidity and mortality rates vary widely among different racial and ethnic groups. For example, rates of invasive cervical cancer in the US vary from a low of 7.2/100 000 among American Indian/Alaska Native women, to 13.1 among African American, and 15.0 among Hispanic women respectively. ${ }^{4}$

The precursor lesion from which invasive cervical cancer develops is cervical intraepithelial neoplasia (CIN). Progression from normal to invasive cervical cancer is thought to occur through increasing grades of cervical dysplasia. The probability of progression of pre-neoplastic lesions to cancer is dependent on the severity of the lesion. CIN I represents very-mild to mild dysplasia. These lesions have a high rate of spontaneous regression $(\sim 60 \%)$ and a low rate of progression to carcinoma. In contrast, approximately $38 \%$ of CIN II and CIN III, moderate to severe dysplasia, will spontaneously regress, while $16-36 \%$ will progress to invasive cervical cancer. ${ }^{5}$ CIN I-III, effectively detected using the Pap smear, can be treated to prevent the development of invasive cervical cancer. In more economically developed countries, Pap smear screening programs have contributed to a large decline in the incidence of invasive cervical cancer. In theory cytologic screening should prevent all cases of cervical cancer. However, due to the logistics of repetitive screening of the large at-risk population, the financial burden of screening, and its failure to be comprehensively applied to populations at-risk, cytologic screening has not eliminated cervical cancer.

Although cervical cancer can be prevented through routine participation in Pap smear screening programs, there are tremendous costs associated with the need for diagnostic follow-up and treatment when abnormalities are found on the Pap smear. Because reporting for CIN is not mandatory, the incidence of CIN in the United States is unknown. However, it is estimated that of the 50 million Pap smears performed annually in the US, $2.8 \%$ to $5.0 \%$ or $1.42-2.5$ million, will be abnormal (e.g., mild, moderate, and severe dysplasia). ${ }^{6,7}$ Although amenable to treatment, CIN adds a significant economic burden to the health care system. Based on the estimated rate of abnormal Pap smears, Morrow and Cozen ${ }^{7}$ calculate that the US annual costs of repeat Pap screening exceeds $\$ 150$ mil- lion, and that the costs of colposcopy, biopsy, and treatment add $\$ 600$ million annually.

To decrease health care costs and patient burden, strategies that could prevent cervical dysplasia are needed. One approach is the development of an HPV vaccine. Until a primary prevention vaccine is widely available and disseminated, other approaches to cervical dysplasia and cancer risk reduction are needed. These approaches include identifying relevant modifiable risk factors, such as those that may contribute to HPV cervical carcinogenesis (e.g., nutritional factors, inflammation, smoking, infection with other sexually acquired infections, hormonal contraceptive use), and modifying these factors to decrease overall cervical dysplasia risk. Case control studies have been very useful in identifying the most important HPV cofactors. Now more information is needed to determine where in cervical carcinogenesis these factors are active and how they affect the natural history of HPV infections. Until recently these questions could not be adequately answered. However, as large prospective studies mature answers to these questions will be forthcoming.

\section{HPV and cervical carcinogenesis}

A diverse and expanding body of evidence indicates that infection with the sexually acquired human papillomavirus (HPV) is the primary risk factor for cervical cancer and plays a central role in cervical carcinogenesis. ${ }^{8}$ The arguments made for this causal association are that $85-100 \%$ of cervical cancer specimens and CIN II-III have presence of HPV DNA, and the association between HPV infection and cervical cancer is specific to a limited number of oncogenic HPV types found in the genital tract. ${ }^{9}$ Strong and consistent associations between HPV infection and cervical cancer have been published from epidemiological studies conducted in the US and worldwide. Prospective studies of HPV infection indicate that women with persistent oncogenic type HPV infections are at a significantly greater risk of developing CIN compared with women who are only transiently infected. ${ }^{10,11}$ Women who are persistently HPV positive are four times more likely to have a persistent lesion of the cervix. ${ }^{12}$ Finally, recent data have suggested that HPV viral load is related to progression of HPV infection to CIN II-III, ${ }^{11,13}$ and to persistence of these pre-malignant lesions. ${ }^{12}$

Different HPV types are related to different cervical lesion grades. ${ }^{9,14} \mathrm{HPV}$ types 16 and 18 are strongly associated with CIN II-III, carcinoma in situ (CIS), and cervical cancer, cervical lesions unlikely to spontaneously regress. They are, therefore, considered "high risk 
type" or oncogenic HPV. HPV types 31, 33, 35, 39, 45, 51,52 , and 58 are associated with an intermediate risk for progression to cervical cancer. Finally, HPV types $6,11,42,43$, and 44 are primarily associated with benign cervical lesions, such as condyloma and CIN I. Since these lesions have a low rate of progression and a high rate of spontaneous regression, the HPV types associated with these lesions are considered "low risk type" or non-oncogenic HPV infections., ${ }^{9,14}$

While a woman's risk for cervical cancer is significantly higher if she has HPV infection, HPV infection alone may be insufficient to cause cervical cancer. Among a cohort of women attending a sexually transmitted disease clinic in Seattle, approximately $28 \%$ of women who were infected with HPV developed CIN. ${ }^{10}$ Although HPV infection is highly associated with cervical lesions, HPV co-factors, such as parity, nutritional factors, inflammation, smoking, infection with other sexually acquired infections, hormonal contraceptive use, may modulate the progression of HPV infection to CIN. ${ }^{15-18}$ For a full review of the role of parity, oral contraceptive use, and tobacco smoking see Munoz et al. ${ }^{18}$ For a full review of the role of other sexually acquired infections, antioxidant nutrient status, and inflammation see Castle et al. ${ }^{19}$ Each co-factor represents different environmental exposures that may work through a common biological mechanism. For example, in case-control and cohort studies, inverse associations between serum carotenoids and $\alpha$-tocopherol, potent antioxidant nutrients, and risk for $\mathrm{CIN}$ and cancer have been observed. ${ }^{20}$ Similarly, inflammation and cigarette smoking, contributors to high oxidant load, have been positively associated with CIN and cancer risk in case-control analyses. ${ }^{19-20}$ Recently smoking has been shown to decrease the probability of clearing an oncogenic infection. ${ }^{21}$ Infection with other sexually acquired infections may act independently of HPV to promote cervical carcinogenesis or may act by inducing an inflammatory response, alter the redox potential of the cell and thereby increase HPV carcinogenesis. Unfortunately few prospective analyses of the association between the contributors of oxidant load status (e.g., antioxidant nutrient status, iron status, smoking, and inflammation) and HPV persistence and CIN risk have been conducted. ${ }^{15,18-22}$

\section{A ssociation between oxidant load and cervical carcinogenesis}

As persistent HPV infection is considered a necessary step in cervical carcinogenesisis researchers have focused attention on understanding the factors that affect the natural history of these infections. For decades researchers have examined whether tobacco use, nutritional status, oral contraceptives, and infections other than HPV are related to invasive cervical cancer. ${ }^{18-19}$ Although many papers have been published, the older literature is unfortunately limited by inadequate assessment of the cause of cervical cancer, HPV infection. Currently two approaches have been used to assess co-factors, that is, the factors that influence progression of HPV infections to clinically significant lesions. The first approach examines the factors associated with HPV persistence utilizing a prospective design with multiple measures of type-specific HPV infection over time. In the second approach analyses of data from case control studies are either limited to those women who have detectable cervical HPV DNA, or HPV infection is controlled for in the analyses. ${ }^{18}$ Using these two approaches cigarette smoking, ${ }^{21}$ Coinfection with Chlamydia trachomatis, ${ }^{19,23}$ and cervical inflammation ${ }^{14,24}$ factors associated with increasing oxidant load have been shown to be independently associated with either HPV persistence or CIN II/III and cancer. Research from our group has demonstrated that antioxidant nutrients (compounds which reduce oxidant load) are associated with decreased risk of HPV persistence among US Hispanics, ${ }^{17}$ an ethnically diverse cohort of US women, ${ }^{15}$ and high-risk Brazilian women.

In addition to the extensively studied HPV co-factors such as smoking which increase oxidant load, there are other factors that are now under investigation that contribute to oxidant load and may have a significant role in carcinogenesis. Several studies have documented that iron serves as a nutrient for cancer cell proliferation and causes oxidative DNA damage through its interaction with oxygen and hydrogen peroxide. ${ }^{25,26}$ Iron is present in cells in various forms, bound to either low molecular weight species, or as an integral part of proteins which are segregated in the various cell compartments. Due to its ability to interact with $\mathrm{O}_{2}$ and $\mathrm{H}_{2} \mathrm{O}_{2}$, iron is believed to be the active metal species responsible for generating reactive oxygen species through Fenton or Haber-Weiss or iron auto-oxidation reactions..$^{27-30}$ In particular, low molecular weight (LMW) iron, the biologically active form of iron that contributes to oxidation reactions, is thought to be the iron metabolite that influences the intracellular concentration of reactive oxygen species. The labile iron pool of cells constitutes a cytosolic fraction of low molecular weight (LMW) chelators bound iron or bioavailable iron, which can be characterized as iron (a) exchangeable and chelatable; (b) easily bioavailable for uptake by ferritin, heme, transferrin, or chelators; (c) metabolically and catalytically reactive for oxidant 
formation and likely responsible for iron toxicity; (d) possibly having regulatory properties which may affect iron responsive element-binding protein activity per se. ${ }^{31,32}$ Recently iron status has been examined as a contributor to carcinogenesis, ${ }^{33-38}$ and has been associated with increased risk of cancer in several epidemiological studies. ${ }^{34,37,38}$

Factors which increase reactive oxygen species, such as smoking, inflammation, bioavailable iron, and reduced antioxidant activity may adversely affect the natural history of HPV infections by increasing the oxidant:antioxidant balance and directly influence transcriptional activity. As such these co-factors may share a common mechanism.

\section{Biological plausibility: Association between oxidant load and cervical carcinogenesis}

Oxidative stress is implicated in the pathogenesis of aging and many chronic diseases. Two general mechanisms contribute to an increase in oxidant load, either excessive generation of reactive oxygen species or inadequate antioxidant defenses. ${ }^{39}$ The association between oxidant load and carcinogenesis has been well studied. ${ }^{40}$ Early research indicated that reactive oxygen species oxidize cellular proteins and DNA that could lead to lethal mutations, and down regulation of the host immune system. More recent research indicates that the role of reactive oxygen species is much greater than just one of damaging cellular proteins and DNA. Reactive oxygen species appear to have a central role in cell signaling by activating AP-1 and NF$\mathrm{kB}$ (transcription factors), cell proliferation, and apoptosis. ${ }^{41}$ In addition, host antioxidant status may affect the virulence of viruses by directly influencing viral evolution. ${ }^{42}$ These more recent findings are particularly relevant to cervical carcinogenesis where viral replication (viral load), transcriptional activity (expression of HPV 16 E6 and E7 proteins), cell proliferation, and apoptosis are pivotal events in cervical carcinogenesis.

Reactive oxygen species appear to have a dual role, one of regulating metabolic activity of cells, and the other in the phagocytic defense mechanism. Using animal and in vitro models, researchers have demonstrated that reactive oxygen species increase the viral titer $^{43}$ and the infectivity of the influenza virus. ${ }^{44} \mathrm{Ad}-$ ministration of antioxidants to animals infected with the influenza virus protected them from the lethal effects of influenza. ${ }^{45}$ In vitro, increases in the cellular oxidant load have been shown to increase the replication of HIV. ${ }^{43,46}$ This effect is thought to be due to the fact that reactive oxygen species activate NF-kB, a nuclear transcriptional factor that is obligatory for HIV replication. ${ }^{46}$ In vitro studies have consistently demonstrated inhibition of NF-kB activation by antioxidants such as $\mathrm{N}$-acetylcysteine, pyrrolidine-dithiocarbamate (PDTC), and the nutrient antioxidant vitamin E ( $\alpha$-tocopherol). ${ }^{47}$

The examples from HIV and influenza virus indicate a role for antioxidants, in the down-regulation of viral replication and expression. Evidence is accumulating to suggest that reactive oxygen species, and their down regulation by antioxidants may work in a similar manner in HPV infection. Activation of the transcriptional factor AP-1, a central transcription factor for the expression of the oncoproteins E6 and E7 of the oncogenic type HPVs, ${ }^{48,49}$ has been shown to be inhibited by antioxidants in in vitro assays. Using an HPV16 immortalized human keratinocyte culture Rosl and colleagues $^{50}$ demonstrated that the antioxidant PDTC selectively suppressed AP-1 induced HPV-16 gene expression. ${ }^{50}$ Similarly, activation of NF-kB occurs in response to cytokines such as interleukin-1 (IL1) and tumor necrosis factor (TNF), cytokines released during an inflammatory response. In addition, NF-kB can be activated by pro-apoptotic stimuli and necrotic stimuli such as oxygen free-radicals and UV light. ${ }^{51}$ Rosl ${ }^{50}$ and others ${ }^{52}$ have suggested that manipulation of the redox potential may be a novel therapeutic approach to interfere with the expression of oncogenic HPVs and other viral induced tumors.

In addition to the effects of oxidants on target cells and cell signaling, the oxidant-antioxidant balance is an important determinant of the immune cell function, affecting maintenance of immune cell membrane lipids, controlling signal transduction in these cells, as well as gene expression of immune cells. ${ }^{53}$ Immune dysfunction, including decreases in natural killer cell activity and T-cell proliferation, has been observed with high oxidant:antioxidant ratios. ${ }^{54}$ By preventing oxidant-induced down-regulation of cellular immunity, higher concentrations of carotenoids and tocopherols may decrease risk for persistent HPV infection and lesion progression by modulating T-cell immunity. Recent data indicate that T-cell immunity, and natural killer cell activity in particular, is important to the loss of HPV infection and CIN regression. ${ }^{55}$

\section{Biological markers of oxidant load}

The concentration of reactive oxygen species cannot be measured directly. However, the products of reactive oxygen species, that is oxidative damage, can be measured and serve as biomarkers of oxidant load. 
Several biomarkers have been identified that provide a measure of oxidative damage to biomolecules. These include amino oxidation products, as well as chemical modifications of protein following carbohydrate or lipid oxidation, such as malondialdehyde (see for full review Onorato and colleagues ${ }^{39}$ ). Elevated plasma levels of malondialdehyde have been reported in many diseases and it is widely used as an index of overall peroxidation. The test for malondialdehyde is based on the reaction of dialdehydes with thiobarbituric acid to form a pink-colored complex. Malondialdehyde is the primary oxidation product of lipids to react with TBA and it forms a product with a higher absorbancy than other oxidation products. These colored adducts are separated by HPLC and measured at $532 \mathrm{~nm}$ or by fluorescence. Although this is an indirect measure of free radical damage, it has been used as a tool to assess oxidative stress. ${ }^{56}$

While there are many compounds that may serve as biological markers of oxidative stress and load, most are of limited utility in epidemiological studies in that they require complex handling and processing, and use of sophisticated analytical techniques. Rapid, more sensitive measures of oxidant load have recently been developed. These newer methods utilizing ELISA assays require small sample volume, can be conducted in routinely stored specimens such as serum, with high throughput in 96 well plate formats.

With interest in the development of reliable markers of oxidant load for use in epidemiological studies, Frenkel and colleagues identified an autoantibody $(\mathrm{aAb})$ to a product of thymidine oxidation ( $\mathrm{HmdU})$. Titer levels of anti-HmdU aAb were subsequently shown to be significantly higher among individuals with various inflammatory diseases such as SLE, immune complex diseases, psoriasis, and cancer. ${ }^{57,58}$ In addition, Frenkel and colleagues demonstrated that alleviation of dermatological inflammatory disease with antioxidant therapy was associated with significant decreases in anti-HmdU aAb levels. Correspondingly, induction of a pro-inflammatory state with UVB irradiation resulted in a rise in anti-HmdU aAb levels. ${ }^{59}$ Extending this work to cancer, Frenkel and colleagues have shown that anti-HmdU aAb levels are associated with breast and colon cancers, ${ }^{60}$ as well as other types of cancer. ${ }^{61}$ In a prospective study, baseline serum anti$\mathrm{HmdU}$ aAb levels of women who developed breast and colon cancers 0.5-6 years post-enrollment had significantly higher baseline anti-HmdU aAb titers than age matched controls. ${ }^{60}$

Anti-HmdU aAb levels are measured using a high through-put ELISA assay, requiring only 100_l serum. Work previously conducted by Frenkel has demon- strated that titer levels can be reliably measured in stored serum samples and that there is low intra-individual variability in titer levels among women over a six-year period, ${ }^{60,62}$ making it ideal for use in large epidemiological studies.

\section{Conclusions}

HPV infection although necessary, appears insufficient to cause cervical cancer. Several HPV co-factors have been proposed, some more or less consistently associated with cervical dysplasia and cancer risk. More research, using prospective cohort designs, is needed to further describe where in carcinogenesis these factors are working and to assess the biological mechanism of these factors. In addition, further research is needed to define the role of various hormonal contraceptive formulations in promoting cervical carcinogenesis. While many interesting scientific questions remain to be answered, results from the numerous epidemiological studies conducted to date indicate that cervical dysplasia and cancer may be reduced if the oxidant antioxidant ratio is shifted to more of an antioxidant profile. In addition to cervical cancer screening, a reduction in cervical cancer incidence may be accomplished by reducing tobacco use, increasing nutritional status, and utilizing barrier contraception to prevent infection with other sexually acquired infections.

\section{References}

1. Parkin D M, Pisani P, Ferlay J. Estimates of the world-wide incidence of 25 major cancers in 1990. Int J Cancer 1999;80:827-841.

2.A merican Cancer Society. Cancer Facts and Figures 2001.Available at: http://www.cancer.org.

3. $N$ ational $C$ ancer Institute. Surveillance Epidemiology and End Results (SEER). A vailable at: http://seer.cancer.org.

4. Mitchell MF,Tortolero-Luna $G, W$ right $T$ et al. Cervical human papillomavirus infection and intraepithelial neoplasia:A review.J $\mathrm{N}$ atl Cancer Inst 1996;21:17-25.

5. Kurman RJ, Henson DE, Herbst AL et al. Interim guidelines for management of abnormal cervical cytology. The $1992 \mathrm{~N}$ ational Cancer Institute W orkshop. JAMA 1994;272:1866-9.

6. Morrow $C P, C$ ozen W . Perspective on cervical cancer:W hy prevent? J Cell Biochem 1995;23(Suppl):61-70.

7. Schiffman MH. N ew epidemiology of human papillomavirus infection and cervical neoplasia.J N atl C ancer Inst 1995;87:1345-1347.

8. Palefsky JM, Holly EA. Molecular virology and epidemiology of human papillomavirus and cervical cancer. Cancer Epidemiol Biomark Prev 1995;4:415-428.

9. Koutsky LA, Holmes KH, C ritchlow CW, Stevens CE, Paaonen J, Beckman AM et al. A cohort study of the risk of cervical intraepithelial neoplasia grade 2 or 3 in relation to papillomavirus infection. $N$ Engl J Med 1992;327:1272-1278. 
10. Schlecht N F, Kulaga S, Robitaille J, Ferreira S, Santos M, Miyamura RA et al. Persistent human papillomavirus infection as a predictor of cervical intraepithelial neoplasia. JAMA 2001;286: 3106-3114.

11. Ho GY, Burk RD, Kein S, Kadish AS, Chang CJ, Papan P et al. Persistent genital human papillomavirus infection as a risk factor for persistent cervical dysplasia.J N atl C ancer Inst 1995;87:1365-1371. 12. C uzick J, Terry G, Ho L, Hollingsworth T, Anderson M. Type-specific human papillomavirus DNA in abnormal smears as a predictor of highgrade cervical intraepithelial neo plasia. Br J Cancer. 1994;69:167-171. 13. Franco EL. Epidemiology of anogenital warts and cancer. En: Reid R, Lörincz A, ed. Human papillomaviruses I. $\mathrm{O}$ bstet Gynecol C lin N orth Am 1996;23:597-623.

14. Castle PE, Hillier SL, Rabe LK, Hildesheim A, Herrero R, Bratti MC et al. An association of cervical inflammation with high-grade cervical neoplasia in women infected with oncogenic human papillomavirus (HPV). Cancer Epidemiol Biomark Prev 2001;10:1021-1027.

15. Sedjo RL, Roe DJ,Abrahamsen M, Harris RB, Craft N , Baldwin S et al. Vitamin A, carotenoids, and risk of persistent oncogenic human papillomavirus infection. Cancer Epidemiol Biomark Prev 2002;11(9):876-884. 16. Giuliano AR, G apstur S. C an cervical dysplasia and cancer be prevented with nutrients? Nutr Rev 1998;56:9-16.

17. Giuliano AR, Papenfuss M, N our M, Canfield LM, Schneider A, Hatch K. Antioxidant nutrients:Associations with persistent human papillomavirus infection. Cancer Epidemiol Biomark Prev 1997;8:917-923.

18. C astellsague X, Muñoz N . Co-factors in HPV carcinogenesis:The role of parity, oral contraceptives and tobacco smoking. J $\mathrm{N}$ atl $\mathrm{C}$ ancer Inst Monograph. 2003;(31):20-28.

19. C astle PE, G iuliano AR. G enital tract infections, cervical inflammation and antioxidant nutriments-assessing their roles as human papillomavirus cofactors. J N atl Cancer Inst Monograph 2003;(31):29-34.

20. Potischman N, Brinton LA. N utrition and cervical dysplasia. Cancer Causes Control 1996;7:113-126.

21. Sedjo RL, Papenfuss MR, Craft N E, G iuliano AR. Effect of plasma micronutrients on clearance of oncogenic human papillomavirus (HPV) infection (U nited States). Cancer Causes Control 2003;14(4):319-326. 22. Giuliano AR. The role of nutrients in the prevention of cervical dysplasia and cancer. N utrition 2000;16(7-8):570-573.

23. Giuliano AR, Papenfuss M, A brahamsen M, Inserra P. Differences in factors associated with oncogenic and non-oncogenic HPV infection at the US-Mexico border. Cancer Epidemiol Biomark Prev 2002;11(9):930-934. 24. Duarte-Franco E, Robitaille J, Santos M, Miyamura R, Rohan T, Ferenczy A et al. HPV Infection as a predictor of the cervical lesion outcome among women with benign cellular changes on PAP cytology. $19^{\text {th }}$ International Papillomavirus Conference; 2001 September 1-7. Costão do Santinho, Florianópolis, Brazil.

25. Johnson S. Iron catalyzed oxidative damage, in spite of normal ferritin and transferrin saturation levels and its possible role in W erner's syndrome, Parkinson's disease, cancer, gout, rheumatoid arthritis, etc. Med Hypotheses 2000;55:242-244.

26. N elson RL. Dietary iron and colorectal cancer risk. Free Radic Biol Med 1992;12:161-168.

27. Comporti M, Signorini C, Buonocore G, Ciccoli L. Iron release, oxidative stress and erythrocyte ageing. Free Radic Biol Med 2002;32:568-576. 28. Toyokuni S. Iron-induced carcinogenesis:The role of redox regulation. Free Radic Biol Med 1996;20:553-566.

29.W elch KD, Davis TZ, Van Eden ME,A ust SD. D eleterious iron-mediated oxidation of biomolecules. Free Radic Biol Med 2002;32:577-583.

30. Huang X, D ai J, Fournier J, A li AM, Z hang Q , Frenkel K. Ferrous ion autoxidation and its chelation in iron-loaded human liver HepG2 cells. Free Radic Biol Med 2002;32:84-92.

31. Breuer W, Epsztejn S, Cabantchik ZI. Dynamics of the cytosolic chelatable iron pool of K562 cells. FEBS Lett 1996;382:304-308.
32. Miller LL, Miller SC, Torti SV,T suji Y,Torti FM. Iron-independent induction of ferritin $\mathrm{H}$ chain by tumor necrosis factor. Proc $\mathrm{N}$ atl $\mathrm{Acad}$ Sci USA 1991:88:4946-4950.

33. Chau N, Benamghar L, Pham Q T, Teculescu D, Rebstock E, Mur JM. Mortality of iron miners in Lorraine (France): Relations between lung function and respiratory symptoms and subsequent mortality. Br J Ind Med 1993;50:1017-1031.

34. Selby JV, Friedman GD. Epidemiologic evidence of an association between body iron stores and risk of cancer. Int J C ancer 1988;41:677-682. 35. Stevens RG. Iron and the risk of cancer. Med O ncol Tumor Pharmacother 1990;7:177-181.

36. Stevens RG, Graubard BI, Micozzi MS, N eriishi K, Blumberg BS. Moderate elevation of body iron level and increased risk of cancer occurrence and death. Int J Cancer 1994;56:364-369.

37. Stevens RG, Jones DY, Micozzi MS, Taylor PR. Body iron stores and the risk of cancer. N Engl J Med 1988;319:1047-1052.

38. W urzelmann JI, Silver A, Schreinemachers D M, Sandler RS, Everson RB. Iron intake and the risk of colorectal cancer. Cancer Epidemiol Biomark Prev 1996;5:503-507.

39. 0 norato JM, Thorpe SR, Baynes JW. Immunohistochemical and ELISA assays for biomarkers of oxidative stress in aging and disease. Ann N Y Acad Sci 1998;854:277-290.

40. N ordberg J,Arner ES. Reactive oxygen species, antioxidants and the mammalian thioredoxin system. Free Radic Biol Med 2001;31:1287-1312. 41. Palmer HJ, Paulson KE. Reactive oxygen species and antioxidants in signal transduction and gene expression. N utr Rev 1997;55:353-361. 42. Beck MA, Shi Q, Morris VC, Levander OA. Rapid genomic evolution of a non-virulent Coxsackievirus B3 in selenium-deficient mice results in selection of identical virulent isolates. N ature Med 1995;1:433-436. 43. Peterhans E. 0 xidants and antioxidants in viral diseases: D isease mechanisms and metabolic regulation.J N utr 1997;127:962S-965S. 44. Hennet T, Perhans E, Stocker R.Alterations in antioxidant defenses in lung and liver of mice infected with influenza-A virus. J Gen Virol 1992;73: 39-46.

45. 0 da T,A kaike T, Hamamoto T, Suzuki F, Hirano T, Maeda H. O xygen radicals in influenza-induced pathogenesis and treatment with pyran polymer-conjugated SO D. Science 1989;244:974-976.

46. Pace GW, Leaf CD.The role of oxidative stress in HIV disease. Free Radic Biol Med 1995;19:523-528.

47. Packer L, SuzukiYJ.Vitamin E and alpha-lipoate: Role in antioxidant recycling and activation of the N F-kB transcription factor. Mol Aspects Med 1993;14:229-239.

48. Cripe TP,A Iderborn A, Anderson RD, Parkinen S, Bergman $P$, Haugen TU et al.Transcriptional activation of the human papillomavirus-16 P97 promoter by an 88-nucleotide enhancer containing distinct cell-dependent and AP-1 responsive modules. $\mathrm{N}$ ew Biol 1990;2:450-463.

49. 0 fford EA, Beard P.A member of the activator protein 1 family found in keratinocytes but not in fibroblasts required for transcription from a human papillomavirus type 18 promoter.J Virol 1990;64:4792-4798. 50. Rosl F, D as BC, Lengert M, G eletneky K, zur Hausen H. Antioxidantinduced changes of the AP-1 transcription complex are paralleled by a selective suppression of human papillomavirus transcription. JVirol 1997;71:362-370.

51. Fontaine V, van der Meijden E, de G raaf J, ter Schegget J, Struyk L.A functional N F-kappaB binding site in the human papillomavirus type 16 long control region. Virology 1997;20;272:40-9.

52. 0 'Byrne KJ, Dalgleish AG. C hronic immune activation and inflammation as the cause of malignancy. Br J C ancer 2001;85:473-483. 53. Meydani S, W u D, Santos M, Hayek M. Antioxidants and immune response in aged persons: 0 verview of present evidence. Am J C lin N utr 1995;62(Suppl):1462S-1467S. 
54. Anderson R, Theron A. Physiological potential of ascorbate, carotene, and $\alpha$-tocopherol individually and in combination in the prevention of tissue damage, carcinogenesis, and immune dysfunction mediated by phagocyte-derived reactive oxidants. World Rev N utr Diet 1998;62:27-5.

55. Khare S, Tang S-C, Pater M, Pater A. C ofactors with HPV infections and oncogenesis. En: Lacey $C$ ed. Papillomavirus reviews: $C$ urrent Research on Papillomaviruses. London: Leeds University Press, 1996.

56.Young, IS and Trimble, ER, Measurement of malondialdehyde in plasma by high performance liquid chromatography with fluorimetric detection. Ann Clin Biochem 1991;28:504-508.

57. Frenkel K, Khasak D, Karkoszka J, Shupack J, Stiller M. Enhanced antibody titers to an oxidized DNA base in inflammatory and neoplastic diseases. Exp Dermatol 1992;1:242-247.

58. Frenkel K, Karkoszka J, Kim E, Taioli E. Recognition of oxidized DN A bases by sera of patients with inflammatory diseases. Free Radic Biol Med 1993;14:483-94.
59. Sasson M, Stiller MJ, Shupack IL, Khasak D, Karkoszka J, Frenkel K. Antibody titers to an oxidized thymidine moiety are altered by systemic pharmacotherapy and ultraviolet B phototherapy.Arch Dermatol Res 1993:285:227-9

60. Frenkel K, Karkoszka J, G lassman T, D ubin N , Toniolo P et al. Serum autoantibodies recognizing 5-hydroxymethyl-2'-deoxyuridine, an oxidized DN A base, as biomarkers of cancer risk in women. Cancer Epidemiol Biomark Prev 1998;7:49-57.

61. Frenkel K, Karkoszka J, Powell J, Berwick M, Mooney LA.Anti-5hydroxymethyl-2'-deoxyuridine ( $\mathrm{HMdU}$ ) autoantibodies (AAB) as biomarkers of cancer risk: $G$ ender differences. Presented at Proceedings of the A merican Association for Cancer Research; 2000, San Francisco (CA), USA.

62. Taioli E, Kinney P, Zhitkovich A, Fulton H, Voitkun V, Cosma G et al. A pplication of reliability models to studies of biomarker validation. Environ Health Perspect 1994;102:306-309. 